\title{
Interactive comment on "Downslope windstorm study in the Isthmus of Tehuantepec using WRF high-resolution simulations" by Miguel A. Prósper et al.
}

\section{Miguel A. Prósper et al.}

prosper.miguelangel@gmail.com

Received and published: 23 May 2019

${ }^{*}$ Supplementary material uploaded: PDF with answers in an easy-readable format + figures.

The paper discusses simulations of one downslope wind event with the limited-area model WRF using multiple nests down to very high resolution (444 m). The study is mostly well written and interesting but needs some substantial editing. I also think it would gain a lot if an additional small sample of Isthmus events could be simulated and discussed (perhaps not using the innermost expensive WRF nest). Doing so would allow to inter-compare events and discuss similarities/differences. Still, the paper might 
be publishable without doing so.

We would like to thank the reviewer for accepting to review this manuscript; we appreciate the positive view of the work. We believe that the modifications suggested will improve the manuscript.

We agree with the reviewer's suggestion in that details about additional Isthmus events could contribute to their better understanding. We have simulated other Tehuantepecer cases occurring in 2013 and we have seen downslope windstorms and hydraulic jumps developing in the mountains east of Chivela pass, as those shown in the paper. The one we selected is the most intense event of the year. We nevertheless prefer to just focus the study in one clear case, given that these phenomena have never been reported before in the area. We leave for future work a more careful study with a sufficient number of cases to investigate the variability these extreme events.

In the revised manuscript we will include in the conclusion section a comment about our preliminary results for other events and the need for a more comprehensive study with a sufficient number of cases to investigate the variability associated with these extreme phenomena.

Next, we address each of the minor concerns presented by the reviewer

Additional minor comments:

1- Page 4, line 21: missing equation

It is true, there is a mistake in this line. In this case we want to refer to Equation 1, which is the Froude number calculation. We will correct it in the revised version.

2- P5, 12: Figure 2c missing

Here we were referring to Figure $1 b$, where d04 and d05 domains are displayed. We correct this typo in the revised version.

3- P6, I 13: 0.5 deg x 0.5 deg
ESDD

Interactive

comment
Printer-friendly version

Discussion paper 
We agree, we will perform the suggested correction in the revised version. 4- P6, 120: rugosity is surface roughness length

ESDD

The reviewer is right; we will replace "rugosity" by "surface roughness length" in the revised version of the manuscript.

5- Table 2: station elevations correct?

Interactive

comment

Yes, it is correct, the elevations are low because both stations are on the coastal plain at the foot of the mountains. The observational data were provided by the Mexican National Laboratory of remote sensors. (https://clima.inifap.gob.mx/Inmysr/Estaciones/MapaEstaciones)

6- Figure 2: Why before and after the event and not at peak intensity?

A map similar to those in Fig. 2 but at peak intensity and focused on the Isthmus is shown in the ensuing figure Fig $3 a$ in the paper. But we agree with the reviewer in that in Fig 2 it makes more sense to show the larger scale situation also at peak intensity than later during the episode. We will now replace Fig2b by the map below, corresponding to 24 December at 03 UTC.

\section{FIGURE 1 ATTACHED}

7- P9, I3: In the results section there should be no hypothesis ("which can potentially)

We will correct the sentence (also including another reviewer's suggestion) as follows: "As shown in the following section 3.2, acceleration on the top of these mountains and to their lee is related to gravity wave activity, which results in the development of strong downslope winds, rotors and hydraulic jumps."

8- P9, 110: whose positions

The correction will be made as suggested.

9- P10, I20: Where can this perfect match be seen? The fulfillment of the listed condi-
Printer-friendly version

Discussion paper 
tions is supported by figures and discussed previously in the text. But we agree with the reviewer in that it should be reminded here. We will change the paragraph as follows:

ESDD

"These conditions are: (1) an asymmetric mountain with steeper lee than windward side (Fig 5), (2) crossed by strong winds (>15m/s) (Fig 5), (3) mostly normal to the barrier (Fig.3, 5). (4) A stable layer above the top and less stable above that (Fig 3d, $6 \mathrm{c}$ ), (5) with cold air advection and large-scale subsidence to maintain the stability (Fig 3d, 6c). Apart from this, (6) reverse wind shear above (Fig 3d, 6c) and (7) no cool pool in the lee (Fig $3 a, 6 b)$, is also desirable. These conditions are all perfectly met for both locations analyzed, as discussed previously, and indeed intense downslope windstorms occur in both cases."

10- Figure 5: It is difficult to understand what is what cross section? Mention "up1" in the caption.

We agree with the reviewer. In the revised version we will indicate in the caption the meaning of UP1 and UP2. These points are the locations where we represented the upwind potential temperature profile (Figure 6).

11- Figure 9b,c: Easier to compare if you use the same domains? Did you discuss the missing northern stratiform cloud deck in the simulations?

We agree with the reviewer's consideration; it would be easier to compare Figure $9 \mathrm{~b}$ with Figure $9 \mathrm{c}$ if we showed them in the same domain. However, it was not possible for us to obtain a clear satellite data representation for domain 05 only. The data used in Figure 9 is directly extracted and postprocessed from GOES-R raw database. We did our best to display the clearest possible image of the small lee cloud formation, and for this purpose we decided to zoom out this image so that the grey color scale is adjusted with the rest of the existent features (the other clouds, the lake, and the sea) and the lee clouds appear more sharply defined. In any case, in the revised version we will add another panel zooming in to exactly match domain 05 for easier comparison with the model results. Regarding the northern stratiform cloud deck

Interactive comment

Printer-friendly version

Discussion paper 
indicated by the reviewer, it is hinted by the model (you can see the edges of it in domain 5 in Fig 9a), but it is likely not correctly simulated because it is only very partially included in the domain and cloud water is not part of the boundary conditions

ESDD for nested grids. We will mention this is the revised version.

Please also note the supplement to this comment:

Interactive

https://www.earth-syst-dynam-discuss.net/esd-2019-3/esd-2019-3-AC2-

supplement.pdf

Interactive comment on Earth Syst. Dynam. Discuss., https://doi.org/10.5194/esd-2019-3, 2019. 


\section{ESDD}

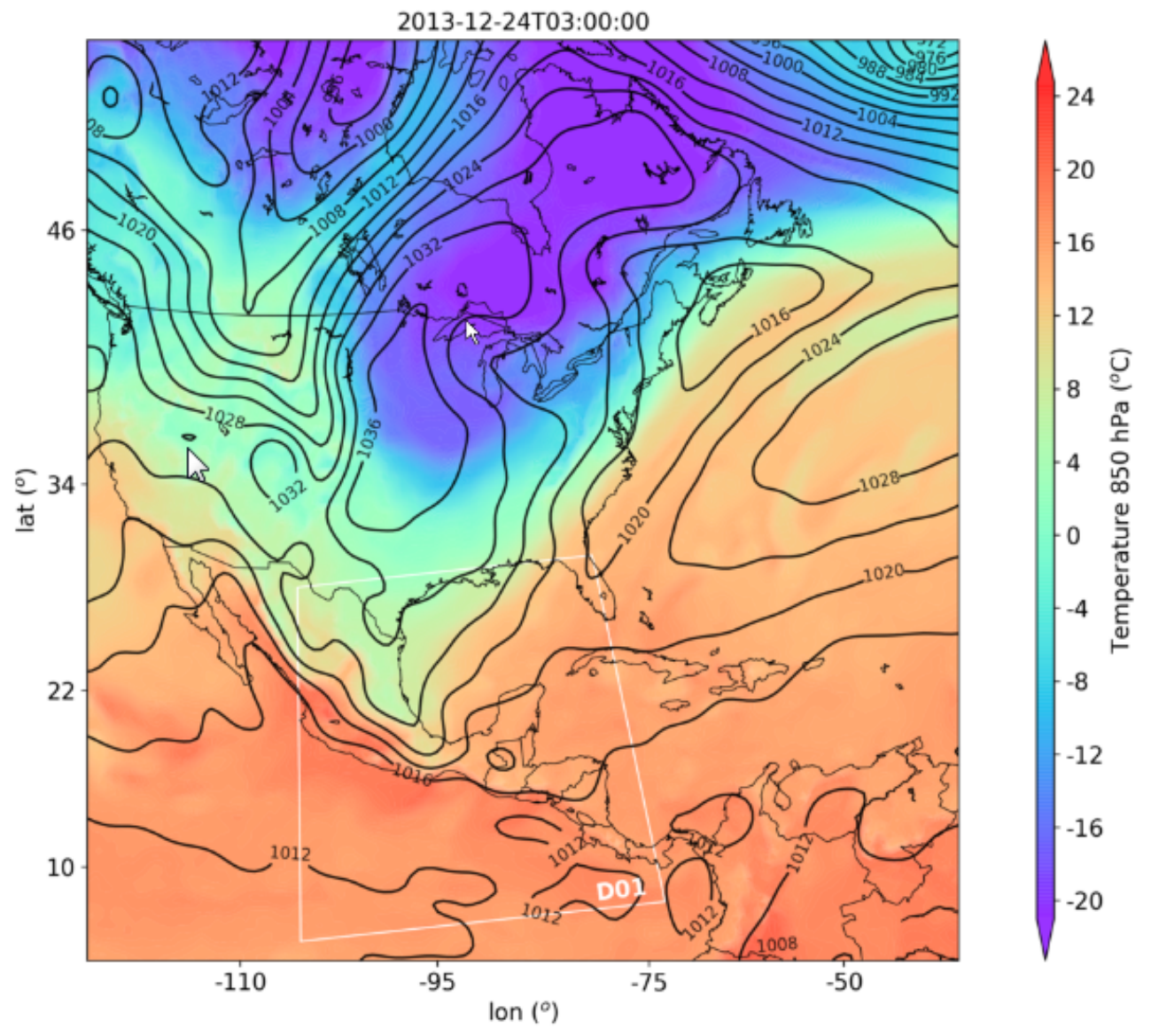

Interactive comment

Fig. 1. 